\title{
O DESEMPENHO DO PARTIDO PROGRESSISTA EM ELEIÇÕES MUNICIPAIS NO RIO GRANDE DO SUL $\left(1996\right.$ - 2012) ${ }^{1}$
}

Vinicius de Lara Ribas ${ }^{2}$

\begin{abstract}
Resumo
O trabalho analisa o desempenho do Partido Progressista (PP) em eleições municipais no Rio Grande do Sul. Em uma análise comparatista entre cinco pleitos, de 1996 a 2012, mapeamos as cidades e regiões em que o partido está mais presente, por meio de dados obtidos junto ao TSE e utilizando o programa de cartomáticaPhilcarto. O objetivo principal do artigo é observar como o Partido Progressista, considerado pela literatura o herdeiro político da Arena, se comportou (no tocante ao resultado) em eleições locais e período democrático. Por fim, concluímos que a força eleitoral do PP no Rio Grande do Sul é a combinação de três fatores apresentados pela literatura, sendo eles: a acomodação do bipartidarismo (1966-1979) no estado de forma menos artificial que em outros subsistemas partidários, o predomínio da direita (ainda que decrescente em outros lugares) nas competições locais e, por fim, uma transição política híbrida e que reuniu elementos conservadores no cenário de democracia.
\end{abstract}

Palavras-chave: Partido Progressista; Eleições municipais; Partidos conservadores; Rio Grande do Sul; Subsistemas partidários.

\begin{abstract}
The article analyzes the performance of the PartidoProgressista (PP) in municipal elections in Rio Grande do Sul (Brazil). On a comparative analysis of five elections, between 1996 and 2012, we mapped the cities and regions where the party is stronger, through data obtained from TSE and using the program Philcarto. The main objective of this article is to see how the PartidoProgressista, considered by literature the political heir of Arena, behaved on local elections in a democratic period. Finally, we conclude that the PP's electoral strength in the Rio Grande do Sul is the combination of three factors, namely: the accommodation of bipartisanship (1966-1979) in the state is less artificial than other party systems, the predominance of the right (downward even elsewhere) in the local competitions and, finally, a hybrid transition, withconservative elements in a democracy.
\end{abstract}

Keywords: Partido Progressista; Municipal elections; Conservativeparties; Rio Grande do Sul; Party systems.

\section{Resumen}

El artículo analizaeldesempeñodelPartido Progressista (PP) enlaseleccionesmunicipales de Rio Grande do Sul (Brasil). En un análisis comparativo de cinco elecciones, entre 1996 y 2012, estudiamos las ciudades y regiones donde el partido es más fuerte, a través de los datos obtenidos de TSE y utilizando el programa Philcarto. El objetivo principal de este artículo es observar el Partido Progressista, considerado por la literatura el heredero político de Arena, se comportó en las elecciones locales en la democracia. Finalmente, llegamos a la conclusión de que la fuerza electoral del PP en el Río Grande del Sur es la combinación de tres factores, a saber: el alojamiento de bipartidismo (19661979) en el estado es menos artificial que otros subsistemas de partidos, el predominio de la derecha (a la baja, incluso en otros lugares) en las competiciones locales y, por último, una transición híbrida, garante elementos conservadores en una democracia.

Palabras clave: Partido Progressista; Eleccionesmunicipales; Partidos conservadores; Rio Grande do Sul; sistemas de partidos.

\footnotetext{
${ }^{1}$ DOI deste artigo: 10.5380/recp.v6i2.42642.

2 Mestrando em Ciência Política na Universidade Federal do Rio Grande do Sul (UFRGS). E-mail: viniciusdelararibas@gmail.com
} 


\section{INTRODUÇÃO ${ }^{3}$}

O bipartidarismo inaugurado pelo regime civil-militar em 1966 acomodou, de um lado, as forças favoráveis à ditadura no partido Aliança Renovadora Nacional (Arena) e, do outro lado, os oposicionistas ao regime, na frente do Movimento Democrático Brasileiro (MDB). Tais partidos disputavam eleições por cargos legislativos, com vantagens nas regras para o partido governista. Diante do insucesso eleitoral da Arena a partir de 1974, a ditaduracivil-militar se viu obrigada a provocar uma liberalização (LAMOUNIER, 1988) no regime e mudança no sistema partidário, extinguindo o bipartidarismo e afrouxando regras para a criação de novas agremiações.

Nesse momento, enquanto a oposição (antes concentrada no MDB) se dividia em mais de um partido, a frente arenista permanecia uma e indivisível. A Arena mudou de nome para Partido Democrático Social (PDS) e conseguiu manter parte considerável da sua força no jogo político. Passando por diversas mudanças de nomenclatura, o atual Partido Progressista é o herdeiro político da Arena e PSD (ALMEIDA, 2004).

Esse trabalho discute o sucessoda "nova roupagem" do partido da ditadura civilmilitarem tempos de democracia. Como observou Rachel Meneguello (2007), há o predomínio da direita no plano municipal desde o retorno das eleições diretas em 1982, entretanto em declínio. Nos municípios do Rio Grande do Sul, argumentaremos a seguir, esse predomínio não está em declínio. O PP continua sendo o partido com o maior número de prefeituras no estado.

Para isso, analisamos o desempenho do Partido Progressista em eleições municipais no Rio Grande do Sul, de forma comparada entre 1996 e 2012. Em uma transição política extremamente lenta e pactuada como foi o caso do Brasil (SANTOS, 2000; SHARE, MAINWARING, 1986; MARENCO, 2007), elementos conservadores conseguiram sobreviver ao sistema democrático (WEFFORT, 1984; 1992). Argumentamos que o predomínio do Partido Progressista em municípios - de pequeno porte e do interior do estado - é uma continuidade do predomínio eleitoral da Arena, partido do regime militar e antecedente do $\mathrm{PP}^{4}$. Tal sucesso se dá, em alguma medida, pela característica apontada pela

\footnotetext{
3 Agradeço as sugestões de Angela Quintanilha Gomes e do parecerista anônimo da Revista Eletrônica de Ciência Política. As possíveis inconsistências no presente trabalho, entretanto, são de minha responsabilidade. ${ }^{4}$ Trabalhos recentes analisaram as elites políticas que estiveram presentes ao longo do regime militar, tanto na Arena quanto no MDB. Carvalho (2008) analisou os parlamentares da Arena e MDB durante o regime. Após o fim da ditadura, a atuação dos parlamentares provenientes do bipartidarismo durante a assembleia constituinte e no autal sistema partidário brasileiro foi tema de análise em Madeira (2011 e 2006, respectivamente). Mais
} 
literatura canônica que defende a existência de um padrão bipartidário e polarizado de competição política no Rio Grande do Sul.

O trabalho divide-se em quatro partes. Na primeira parte, apresentamos o sistema partidário brasileiro entre 1946 e 1979, variando do multipartidarismo da democracia (19461964) para o bipartidarismo ditatorial (1966-1979) e o multipartidarismo criado pelo regime civil-miliar, em 1979, em voga atualmente. Em seguida, apresentamos a competição políticopartidária no Rio Grande do Sul, desde a imposição do bipartidarismo, no final de 1965 e início de 1966. A terceira parte é dedicada à análise dos dados eleitorais, em disputas para prefeituras, entre 1996 e 2012, com foco no Partido Progressista. A parte final é dedicada às considerações finais.

\section{SISTEMA PARTIDÁRIO NO BRASIL: DA DITADURA A REDEMOCRATIZAÇÃO}

O golpe civil-militar de primeiro de abril de 1964 encerrou a primeira experiência democrática brasileira, inaugurada em 1946. Sem os pilares de uma "real democracia de massas" e um período de "instabilidade endêmica", essa experiência democrática ficou conhecida na literatura como "democracia populista" (SOUZA, 1985, p. 73-4), sendo marcada por soluções autoritárias como respostas as crises políticas. A cassação do Partido Comunista Brasileiro (PCB), em 1947, e o "golpe branco" que garantiu a posse de Juscelino Kubitscheck, em 1955, são dois exemplos do modus operandi da elite política à época, que não possuía muito apreço pela democracia. Argelina Figueiredo defende, inclusive, que o golpe militar foi resultado justamente dessa falta de apreço peloregime democrático, tanto pelos grupos de esquerda organizados em partidos políticos, quanto pelos grupos de direita que tentavam recuperar parte do poder perdido com a massificação da luta política (FIGUEIREDO, 1983).

Em que pese o período seja de instabilidade política e "saídas autoritárias", Bolívar Lamounier (1985) observa ser essa o início da "questão democrática" no Brasil. Foi no período em questão que partidos se organizaram para vencer eleições e ocupar o governo, em uma "passagem da política de 'notáveis' para a política de 'massas" (SOUZA, 1985, p. 73) inédita na política brasileira.

especificamente no caso do Rio Grande do Sul e sua elite política conservadora, a trajetória política de prefeitos arenistas no Rio Grande do Sul está Madeira e Girardi (2014). 
Os partidos principais do momento, entretanto, foram criados no seio da ditadura do Estado Novo: Partido Trabalhista Brasileiro (PTB), organizado por Getúlio Vargas para arregimentar operários urbanos e servir de "anteparo" ao crescimento do PCB (DELGADO, 1989); Partido Social Democrático (PSD), organizado por Vargas para reunir uma antiga elite política, ligada sobretudo aos interventores estaduais (HIPÓLITO, 1985); e, por fim, a força anti-varguista, União Democrática Nacional (UDN), organizada como oposição ao Estado Novo. A competição político-eleitoral do período, marcada pelas vitórias da aliança PSDPTB, não agradava aos udenistas, que mais de uma vez defenderam golpe de Estado (BENEVIDES, 1981).

Mas, em 1964, com o golpe civil-militar logrando “êxito” ao depor João Goulart, os políticos aliados à UDN viram-se pela primeira vez com uma chance real de chegar ao poder. A aliança civil-militar costurada por eles (pela parte civil) havia vingado e um general estava na Presidência da República, com a promessa de garantir as eleições presidenciais em outubro de 1965.

Não demorou muito para se perceber que a "solução autoritária" a crise política duraria um pouco mais do que o previsto. A edição do Ato Institucional número 2 (AI-2), em 1965, adiou as eleições presidenciais e deu fim ao sistema partidário. Tal movimento por parte do regime "castigou” o PTB e foi saudado pela UDN, que não via outra saída para melhorar sua imagem diante do eleitorado brasileiro.

O AI-2 estabeleceu regras para a formação de um sistema bipartidário com um partido forte, governista, e um partido fraco e oposicionista. Nascia assim a Aliança Renovadora Nacional (Arena), sustentação do regime autoritário, e o Movimento Democrático Brasileiro (MDB) ${ }^{5}$. A extinção do sistema multipartidário não encontrou resistências por parte dos políticos conservadores (pertencentes a UDN), que apoiaram o golpe civil-militar. Estes foram, inclusive, de certa forma beneficiados pelo fim da UDN, desgastada publicamente ${ }^{6}$. Scott Mainwaring, Rachel Meneguello e Timothy Power explicam a nova feição da competição eleitoral brasileira, adquirida depois do golpe:

O regime militar teve ampla aceitação pelos partidos conservadores, tanto que o primeiro presidente militar, general Humberto Castelo Branco, teve pouca dificuldade em garantir as adesões de muitos políticos no governo. Nos seus primeiros dois anos no cargo, governou com o apoio de uma

\footnotetext{
${ }^{5}$ Para mais informações sobre a Arena, ver Grinberg (2009), sobre o MDB, ver Kinzo (1988).

${ }^{6}$ Kinzo observa que em torno de $90 \%$ dos parlamentares da UDN migraram para a Arena. O PSD se dividiu: $64 \%$ foram para a Arena e 36\% para o MDB. Do PTB, 70\% constitui o MDB (KINZO, 1980, p. 221).
} 
facção majoritária no Congresso, o Bloco Parlamentar da Revolução, ainda baseado nos velhos partidos de 1945-1964. Foi em outubro de 1965, com o Ato Institucional n ${ }^{\circ} .2$ (AI-2) que extinguiu todos os partidos e, em seguida, com o Ato Complementar $\mathrm{n}^{\circ}$. 4, que estabeleceu o sistema bipartidário, tendo início uma clivagem que iria caracterizar a política brasileira durante uma geração: autoritários versus conservadores (MAINWARING; MENEGUELLO; POWER, 2000, p. 24).

Deste modo, a inauguração da Arena e do MDB se deu de forma artificial, o que levou o governo autoritário a criar casuísmos eleitorais", como as "sublegendas" nos partidos, inaugurada em novembro de 1965. Como exemplifica Jairo Nicolau, "caso utiliza-se a sublegenda, um partido poderia apresentar até três nomes para a disputa do mesmo cargo, o que significa dizer que em uma eleição para prefeito, por exemplo, poderiam concorrer até seis nomes, três da Arena e três do MDB” (NICOLAU, 2012, p. 108). Estes casuísmos iniciais demonstram a falta de enraizamento dos novos partidos entre os eleitores e políticos, que disputavam votos dentro do próprio partido.

A competição entre Arena e $\mathrm{MDB}$, ou "autoritários versus conservadores" respectivamente, durou o tempo em que a economia suportou a dinâmica do regime civilmilitar e a organização interna do partido governista. Em 1974, crescia a insatisfação da população frente à situação econômica do Brasil, sobretudo com o aumento da inflação (KINZO, 1988, P. 153). Por outro lado, a sublegenda - responsável por abrigar oligarquias distintas num mesmo partido - trazia encargos aos arenistas: a falta de organização e disputas internas fizeram com que o partido se apresentasse fraco frente ao MDB, oposição que há meses preparava uma campanha para o período eleitoral ${ }^{8}$. Fabio Wanderley Reis explica a importância da derrota eleitoral da Arena para o regime:

Facilitada pelo quadro político-partidário bipolar, que passou a fornecer claro molde institucional para contraposições simples como as que se dão na consciência popular entre categorias tais como "ricos" e "pobres", "povo" e "governo", tal retomada das tendências anteriores se deu em 1974, quando o MDB enfraquece pela primeira vez as preferências populares e obteve inequívoca vitória nas eleições para o Senado. Abre-se, a partir daí, nova fase nas manobras institucionais do regime, que buscam agora neutralizar o potencial de mobilização do voto popular com que o MDB passa a contar sobretudo nos centros urbanos, culminando na liquidação forçosa do bipartidarismo e na restauração de uma estrutura

\footnotetext{
7 "Casuísmos eleitorais" forammovimentos do regime civil-militar para modificar constantemente as regras eleitorais em seu favor, viciando os resultados.

8 A “anti-candidatura” de Ulysses Guimarães para a Presidência da República, em 1973, ilustra bem a vontade do MDB em ser competitivo. Mesmo em um cenário de escolha de Presidente no Colégio Eleitoral, Ulysses e o MDB se lançam como candidatos e percorrem o Brasil em campanha, mas também montando diretórios do MDB e preparando o partido para as eleições legislativas de 1974 (KINZO, 1988).
} 
multipartidária através de poderosos incentivos legais e políticos (REIS, 1983, p. 113).

Diante da sangria arenista e fortalecimento do $\mathrm{MDB}$, a solução criada pelo governo civil-militar a fim de controlar a liberalização do regime foi, no tocante ao sistema partidário, a dissolução do bipartidarismo em 1979 e estabelecimento de novas regras para a criação de partidos políticos. A configuração partidária originária do bipartidarismo pode ser observada na Imagem 01:

Imagem 01 - Principais mudanças no quadro partidáriodo Brasil (Reforma de 1979) e origens do atual Partido Progressista

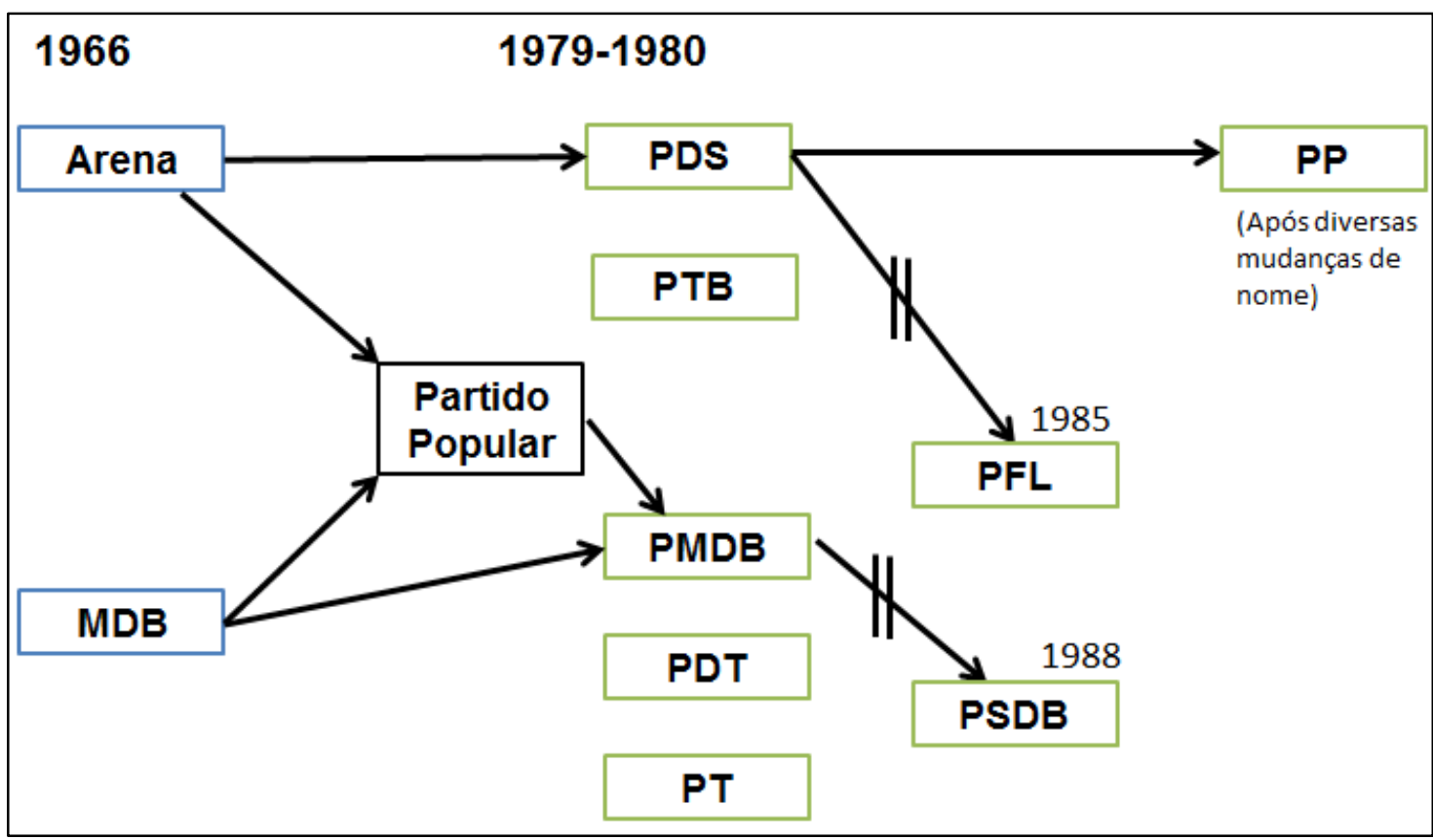

Fonte: construção do autor.

Como escreveu Scott Mainwaring (2001, p. 322), o fim do bipartidarismo era uma antiga reivindicação da oposição, entretanto, o governo utilizou-se desta reivindicação para enfraquecê-la. O partido do governo permaneceu uno, agrupado na nova sigla PDS, enquanto que os oposicionistasdividiram-se em cinco partidos: o PMDB reunia o antigo MDB e, mais tarde, deputados do recente Partido Popular; o PTB e PDT buscavam herdar as antigas tradições do trabalhismo e do varguirsmo, construídas no período anterior a ditadura civil-militar; por fim, o PT surgia como um partido externo ao parlamento e de bases sociais (Meneguello, 1989).

A intenção do governo de manter um partido forte como seu porta-voz, entretanto, durou pouco. Como demonstrado na Figura 1, o PDS sofre uma quebra quando uma 
dissidência do partido adota a estratégia de apoiar Tancredo Neves, candidato da oposição, no Colégio Eleitoral que escolheria o sucessor do último presidente militar. A dissidência foi chamada de Partido da Frente Liberal, reunindo antigos aliados do regime no apoio do candidato do PMDB.

\section{RIO GRANDE DO SUL: A FORÇA DO BIPARTIDARISMO HISTÓRICO}

O bipartidarismo de 1965 acomodou-se no Rio Grande do Sul de maneira bem menos artificial se comparado a outras unidades da federação, tendo em vista esse possuir uma tradição de competição política polarizada desde o século XIX, quando as competições davam-se pela organização de clãs e a disputa pelo poder no estado se deu entre dois grupos principais (TRINDADE; NOLL; 1991, p. 27). Esta polarização construída pelo regime militar encontrou respaldo no cenário anterior, proveniente da primeira experiência democrática brasileira, a saber: um confronto entre PTB versusanti-PTB.

Durante o período democrático, de 1946 a 1964, as forças eleitorais gaúchas organizaram-se entre trabalhistas (organizados no PTB, localizados à esquerda no espectro político) versusanti-trabalhistas (organizados em outros partidos). O PTB controlava grande parte dos municípios e demais partidos, menores e menos expressivos, estavam distribuídos pelo resto do estado. Com isto, prosseguia no Rio Grande do Sul o antigo e secular padrão de disputa polarizada. Nas palavras de HélgioTrindade e Izabel Noll:

A confrontação PTB/anti-PTB no pós-45, fugindo ao padrão brasileiro dominante, em grande medida, é a reprodução no interior do sistema multipartidário da polarização preexistente, cuja origem histórica configurou-se no estatuário da Revolução dos Farrapos, definindo o processo de estruturação das opções políticas regionais. Esse padrão torna mais consistente no Império a competição entre conservadores e liberais e explica, também, na República Velha, o estilo radicalizado do confronto entre conservadores-liberais (federalistas e libertadores) e conservadoresautoritários (republicanos positivistas) (TRINDADE; NOLL, 1991, p. 68).

Trindade e Noll argumentam ainda que "a polarização constatada ao nível dos dados globais do estado na votação para Assembleia Legislativa foi também constatada, através da análise das coligações locais, nas eleições municipais majoritárias municipais de 1951 a 1963” (TRINDADE; NOLL, 1991, p. 72). Deste modo, a polarização, delimitada entre duas formas de se organizar, respaldava preferências estáveis dos eleitores. 
Com a Reforma Partidária de 1979 e o surgimento de novos partidos, as disputas municipais no cenário gaúcho recuperam, em 1982 e depois em 1986, a "tradição petebista" do estado, que exigia um novo cenário, mas ainda polarizado entre dois grupos políticos. Para Trindade e Noll,

A recuperação no Rio Grande do Sul da tradição petebista latosensu se manifesta com o desempenho do PMDB e do PDT nas eleições de 1982 e 1986, onde ocorre nitidamente o seguinte processo: PMDB/PDT voltam a controlar $52,0 \%$ dos municípios do estado, enquanto a força do PDS se reduz a menos de $10 \%$. Ademais, a força do PMDB/PDT, que sempre foi significativa nos municípios de maior eleitorado, torna-se também dominante nos de menos de 20 mil eleitores (TRINDADE; NOLL, 2004, p. 107).

Desenha-se no estado um novo cenário, em que "o espaço do PMDB seja [foi] agressivamente ocupado pelo PDT" (TRINDADE; NOLL, 2004, p. 95), alterando-se as forças partidárias, mas persistindo no fim do regime militar e limiar da Nova República, o padrão histórico da polarização política. De um lado o PDS, que conquista em 1982 o governo do estado e em torno de $48 \%$ dos executivos municipais. Por outro lado, o PMDB e PDT passam a controlar 52\% das prefeituras. Nas eleições de 1986, o PMDB elegeu o governador. Nas eleições seguintes, em 1990, ganhou o PDT.No plano das eleições municipais, entre 1996 e 2012, a disputa no RS organizou-se conforme demostrada no Quadro 01.

\begin{tabular}{|c|c|c|c|c|c|}
\hline \multicolumn{7}{|c|}{ QUADRO 01 } \\
\hline \multicolumn{7}{|c|}{ Eleições municipais no Rio Grande do Sul (1996-2012) } \\
\hline PP & 1996 & 2000 & 2004 & 2008 & 2012 \\
\hline PMDB & 142 & 174 & 134 & 148 & 134 \\
\hline PDT & 158 & 139 & 137 & 144 & 133 \\
\hline PT & 85 & 78 & 97 & 65 & 70 \\
\hline Outros* & 26 & 35 & 43 & 64 & 72 \\
\hline Total & 60 & 71 & 85 & 81 & 88 \\
\hline * PTB, PSDB, DEM (ex-PFL), PSB, PPS, PHS, PR, PSD (a partir de 2012), PPL, PV, PSC, \\
\hline \multicolumn{7}{|l|}{ PTdoB e PL. } \\
\hline Fonte: TSE.
\end{tabular}




\section{DEMOCRACIA E ELEIÇÕES MUNICIPAIS NO RIO GRANDE DO SUL: A FORÇA DA ANTIGA ARENA}

O atual Partido Progressista, fruto da antiga Aliança Renovadora Nacional, é o resultado de um processo que nos remonta ao golpe militar e formação do sistema bipartidário brasileiro. No Rio Grande do Sul, como observado na seção anterior do texto, o partido construído como suporte ao autoritarismo teve sempre muito poder ao longo de sua trajetória.

O bom desempenho da Arena nas urnas, somado aos casuísmos eleitorais editados pelo regime e as cassações de parlamentares da oposição, permitiu o predomínio de fato do partido no sistema bipartidário até 1974 . No pleito realizado nesse ano, o voto no MDB consolidou-se como um voto de oposição à ditadura, sendo este o grande vencedor das eleições parlamentares.

Com a liberalização do regime como resultado da pressão das urnas, iniciou-se a Reforma Partidária de 1979, modificando a “Arena” para Partido Democrático Social (PDS). No PDS, cerca de 90\% dos deputados federais pertencia anteriormente a Arena (KINZO, 1988, p. 209). A mudança de nome ocorreu, sobretudo, na tentativa de desvincular-se aos anos ditatoriais, mas congregava, segundo Almeida, a base de apoio do regime:

O PDS congregou as forças favoráveis ao sistema político implantado pelos militares em 1964. É nesse partido que vão se instalar as principais lideranças da Arena: Aureliano Chaves, vice-presidente de Figueiredo; Mário Andreazza, ex-ministro do governo Médici; Paulo Maluf, exgovernador de São Paulo, entre tantos outros. Obteve seu registro definitivo em 28 de maio de 1981. No ano de 1982 o partido investiu em propaganda na expectativa de obter parte dos votos disponíveis no país para conseguir a maioria dos votos no colégio eleitoral que elegeria o Presidente (ALMEIDA, 2004, p. 43).

Almeida defende, também, que a mudança de nome demonstra a falta de prestígio do partido perante o eleitor. Durante o período da transição, o PDS lançou candidato à presidência da República (Paulo Maluf, em 1989), mas perdeu considerável força nos estados, onde os governadores eram em sua maioria do PMDB.

A partir da chegada de Paulo Maluf - principal liderança do partido - à prefeitura de São Paulo, em 1992, ocorre um processo de mudança estrutural na sigla, que culmina com a fusão ao Partido Democrata Cristão (PDC) e modificação da sigla para Partido Progressista 
Reformador (PPR). O PPR disputou apenas as eleições de 1994, quando novamente mudou de nome. Nestas eleições,

[...] o candidato a Presidência da República pelo partido, Esperidião Amin, obtém somente $3 \%$ dos votos, conseguindo um tímido sexto lugar na disputa. O PPR consegue, no entanto, eleger 52 deputados federais, formando a quarta maior bancada na Câmara. Nas eleições estaduais o partido elege três dos 27 governadores (Oleir Cameli, do Acre, Amazonino Mendes, do Amazonas e Siqueira Campos, do Tocantins), enquanto o PMDB elege nove e o PSDB seis. O partido elege ainda 112 deputados estaduais, mais de $10 \%$ do total de deputados do país, seu melhor desempenho desde 1982 nas Assembleias Estaduais. [...] A despeito do sexto lugar obtido por Amin na eleição presidencial e da derrota do candidato apoiado por Paulo Maluf em São Paulo, o PDS sob sua nova denominação (PPR) obtém em 1994 seu melhor desempenho desde 1982 (ALMEIDA, 2004, p. 58).

Em que pese o bom desempenho eleitoral que havia conquistado, comparado às atuações em pleitos anteriores, o partido novamente se reformula, fusionando-se ao PP (também um partido que disputou apenas o pleito de 94, resultado da fusão do PTR ao PST) e muda seu nome para Partido Progressista Brasileiro, o PPB, em 1995.

A última mudança de nome ocorreu em 2004, quando a agremiação subtrai de seu nome o vocábulo "brasileiro" e passa a ser conhecida apenas como Partido Progressista (PP). De acordo com Almeida, a mudança do nome não se mostrou de início eficiente, pois os resultados municipais de 2004, quando o partido elege 551 prefeitos pelo território nacional, foram inferiores aos resultados alcançados em 2000.

O desempenho do Partido Progressista na conquista de prefeituras em todo o Brasil, ao longo das eleições, tem se mostrado muito aquém do que o mesmo consegue realizar no Rio Grande do Sul, onde é a agremiação que mais possui executivos municipais e um número considerável de militantes. Na última eleição presidencial em que participou com candidato próprio, o PP/RS obteve 8,19\% dos votos no estado (QUADROS, 2012, p. 45). Segundo Almeida, “o Rio Grande do Sul é o estado onde o PP tem a maior penetração no país: é onde o partido tem o maior número de deputados federais, deputados estaduais, prefeitos, vice-prefeitos e vereadores" (2004, p. 63).

O Quadro 02 demonstra o número e a percentagem de prefeituras conquistadas pelo PP no Brasil e no Rio Grande do Sul entre 1996 e 2012: 


\begin{tabular}{|c|c|c|c|c|c|c|}
\hline \multicolumn{7}{|c|}{ QUADRO 02 } \\
\hline \multirow{3}{*}{ Brasil sem RS } & $\mathrm{N}$ & 483 & 444 & 417 & 401 & 338 \\
\hline & $\%$ & 9,78 & 8,77 & 8,23 & 7,88 & 6,68 \\
\hline \multirow{2}{*}{ RS } & $\mathrm{N}$ & 142 & 174 & 134 & 148 & 134 \\
\hline \multirow{2}{*}{ Total } & $\%$ & 30,14 & 35,01 & 27,01 & 29,48 & 26,96 \\
\hline & $\mathrm{N}$ & 625 & 618 & 551 & 549 & 472 \\
\hline Fonte: TSE. & $\%$ & 11,55 & 11,12 & 10,87 & 9,82 & 8,49 \\
\hline
\end{tabular}

O estado do Rio Grande do Sul, em relação ao restante do Brasil, é o que possui, portanto, o maior número de prefeituras ligadas ao Partido Progressista, elevando seu percentual total de forma significativa. A parcela no estado é ainda a maior dentro deste em relação aos outros partidos. Ou seja, o PP/RS é o partido com maior número de prefeituras, se comparado a outros partidos dentro do estado.A evolução eleitoral em executivos municipais é demonstrada no Gráfico 01:

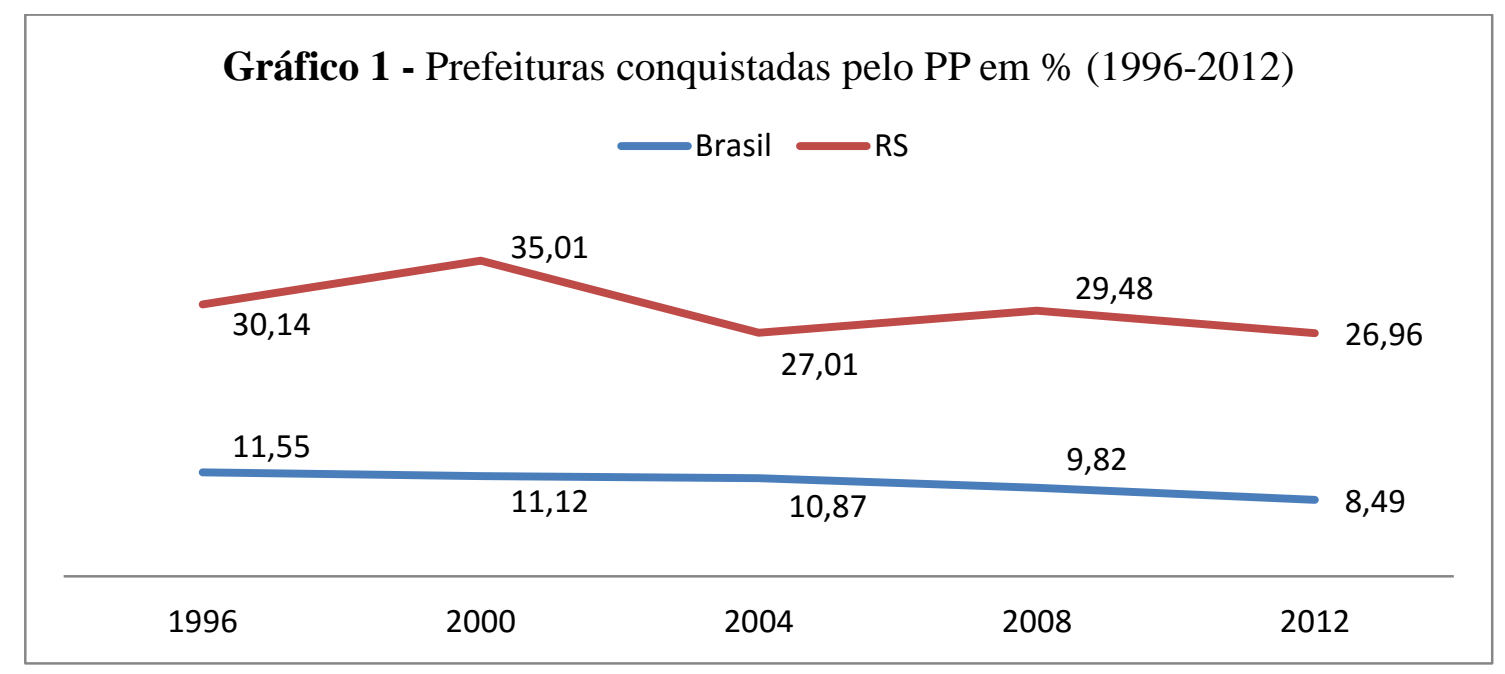

Fonte: construção do autor com dados do TSE.

Com um desempenho eleitoral bem superior se comparado ao resto do Brasil, o PP tem um alto grau de estabilidade nos seus resultados eleitorais dentro do estado quando tratamos de eleições municipais majoritárias. Entretanto, essa condição de "vitorioso" vem sofrendo derrotas eleitorais, ainda que pequenas. Pode-se perceber tal fato comparando as eleições do final dos anos 90 e início dos anos 2000 com as eleições de 2012: o partido perdeu quase $7 \%$ dos seus executivos locais.

Em que pese seja o partido que possui o maior número de prefeituras, é importante notar que o PP não penetra em municípios maiores, ficando relegado aos municípios do 
interior e com menor população. Meneguello (2007) aponta que partidos de direita estão em declínio eleitoral no Brasil e, além disso, concentram sua força restante no interior do país. Tal afirmação é corroborada com os dados do PP no Rio Grande do Sul: a região Metropolitana de Porto Alegre, região mais industrializada e com maior densidade populacional do estado, é a que menos possui prefeituras do Partido Progressista (ver Quadro 03 e Imagem 02).

Ao longo das cinco eleições aqui estudadas, a presença do Partido Progressista no RS não se deu de forma concentrada regionalmente, mas sim dispersa pelo estado. O Quadro 03 demonstra a frequência, em percentagem, do partido nas sete mesorregiões do Rio Grande do Sul, a partir das eleições do segundo milênio. A Imagem 02, demonstra, em azul, as prefeituras ocupadas pelo partido nas eleições de 2000, 2004, 2008 e 2012.

\begin{tabular}{|c|c|c|c|c|}
\hline \multicolumn{5}{|c|}{ QUADRO 03 } \\
\hline \multicolumn{5}{|c|}{ Partido Progressista: presença (em \%) nas mesorregiões do Rio Grande do Sul } \\
& $(\mathbf{2 0 0 0 - 2 0 1 2})$ \\
\hline & 2000 & 2004 & 2008 & 2012 \\
\hline Centro Ocidental & 54,83 & 38,7 & 45,16 & 29,03 \\
\hline Centro Oriental & 42,59 & 27,77 & 37,03 & 31,48 \\
\hline Metropolitana & 24,48 & 19,38 & 22,44 & 16,32 \\
\hline Nordeste & 44,44 & 27,77 & 18,51 & 29,62 \\
\hline Noroeste & 35,18 & 29,62 & 31,94 & 29,62 \\
\hline Sudeste & 24 & 16 & 28 & 24 \\
\hline Sudoeste & 26,31 & 15,78 & 31,57 & 31,57 \\
\hline Fonte: TSE. & & & & \\
\hline
\end{tabular}


Imagem 02 - Partido Progressista - Eleições 2000 - 2012

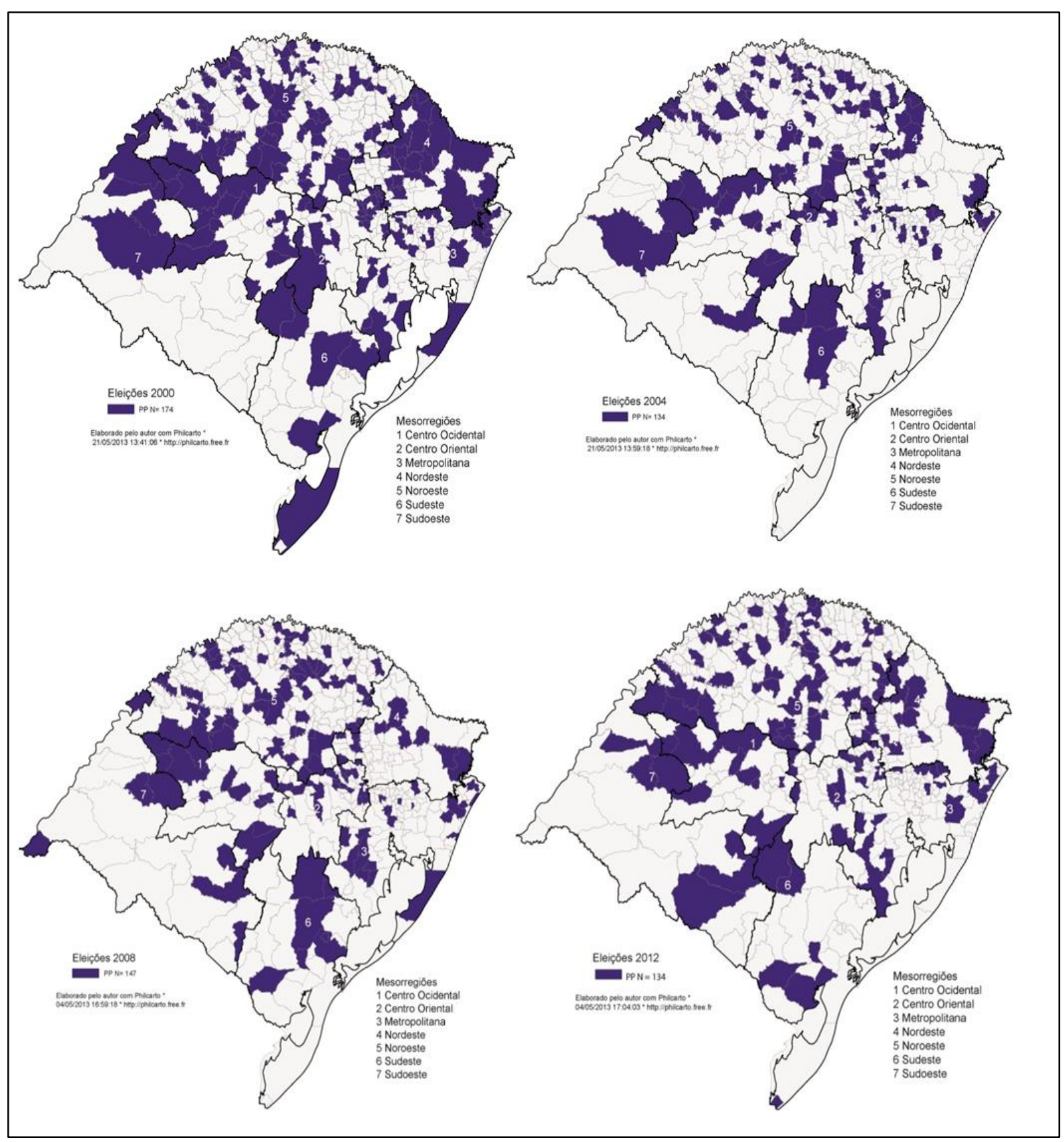

Fonte: construção do autor com dados do TSE.

No pleito de 2000, há uma densidade de prefeituras ligadas a o PP entre as regiões Centro Oriental, Noroeste e Sudoeste. Entretanto, no Sudoeste é onde o partido menos consegue eleger prefeitos. As regiões Centro Ocidental e Nordeste foram, em 2000, as quais o PP conseguiu mais resultados positivos: na primeira, mais da metade dos municípios estavam com administrações progressistas; na segunda, em torno de $45 \%$ das cidades. 
Em 2004, os resultados positivos ao PP diminuem consideravelmente quando comparados ao pleito anterior. O partido perde em torno de $8 \%$ das prefeituras que administrava. A densidade do mesmo nas regiões Centro Ocidental e sobretudo no Nordeste gaúcho já não é mais tão expressiva quanto em 2000. A região em que o PP menos perdeu neste pleito foi ao Noroeste do estado, onde os municípios são menores.

No pleito de 2008, o partido recupera-se em todas as regiões, exceto o Nordeste, onde este perde ainda mais prefeituras. A região Centro Oriental é onde o PP atinge os melhores resultados no ano, em que ele recupera 10\% dos municípios. O Sudoeste gaúcho fica relegado a pouca densidade de administrações progressistas, com em torno de $31 \%$ da região.

De acordo com os dados, a presença do PP na região Centro Ocidental (número um dos mapas apresentados), localizada no interior do estado, diminuiu de forma considerável em doze anos - quase $26 \%$ dos municípios que possuía. Entre este período, a presença do partido em Executivos municipais oscilou, mas sem nunca atingir a marca de 2000, ao qual possuia mais da metade das prefeituras centro-ocidentais do RS.

O PP na região Centro Oriental (número dois) experimentou um período de oscilação para, então, estabilizar-se nas duas últimas eleições passaram para outros partidos. Como observamos no Gráfico 03, no período estudado, a eleição de 2000 foi a que melhor trouxe resultados ao partido, enquanto que a sua posterior, em 2004, foi a qual onde o partido apresentou pior desempenho até então. Com pouco mais de $42 \%$ da região na primeira eleição do milênio, sua presença caiu para apenas quase $28 \%$ na região, para enfim estabilizar na dezena dos 30\% de Executivos centro-orientais gaúchos.

A região Metropolitana de Porto Alegre (número três), a mais industrializada do estado, é o local onde o Partido Progressita apresenta o pior desempenho no estado. Em doze anos, seus resultados caíram em torno de oito pontos porcentuais. Atualmente, a presença do PP conta com dezesseis dos 98 municípios na região, o que resulta em torno de $16 \%$ de Executivos municpais.

O Nordeste do estado (número quatro) é a região em que o partido mais se recuperou na última eleição, ocorrida em 2012. Enquanto que em 2008 o partido havia conquistado menos de 20\% das prefeituras do nordeste gaúcho, em 2012 há uma recuperação e quase 
$30 \%$ da região volta a ser governada pelo PP. O número não chega a atingir, entretanto, a marca das eleições 2000, onde o partido conquistou quase 45\% da mesorregião.

A região Noroeste (número cinco) é a mais estável para os resultados eleitorais do PP. Entre 2000 e 2012, o partido oscilou entre os 35\% a 29\% das prefeituras locais. O desempenho de 2004 equipara-se ao de 2012: nestes dois pleitos o Partido Progressista conquista quase $30 \%$ dos municípios noroestinos.

$\mathrm{Na}$ região Sudeste (número seis dos mapas apresentados), o partido sofre um crescimento (em 2008) e uma retração (em 2004) ao longo do período estudado. Seus resultados de 2012, entretanto, igualam-se ao cenário de 2000. Por fim, na região Sudoeste (número sete), o PP cresceu eleitoralmente nos últimos anos. Enquanto que em 2004 o partido detinha 15\% das prefeituras, esse número dobrou em 2008 e manteve-se em 2012, portanto, com pouco mais de $30 \%$ dos Executivos locais.

Comparando os mapas eleitorais, podemos perceber, ainda, que nas últimas eleições a presença do PP nas fronteiras caiu de forma considerável, chegando quase à nulidade nas eleições de 2012. Nos últimos anos o partido se capilarizou mais no estado, comparado ao pleito de 2000, onde este estava mais concentrado. Atualmente, as prefeituras controladas pelo Partido Progressista estão dispersas por todo o Rio Grande do Sul, não se concentrando em alguma região específica.

\section{CONSIDERAÇÕES FINAIS}

Buscamos, nesse trabalho, analisar as vitórias eleitorais do Partido Progressista, herdeiro político da Arena, nos municípios do Rio Grande do Sul entre 1996 e 2012. O estado tem, há muito tempo, uma tradição "bipartidária”, reforçada entre o período de 1966 a 1979 - na dicotomiaArena versus MDB - e o PP se beneficiou dela para continuar ganhando eleições municipais no regime democrático.

Algumas questões podem nos ajudar a dar uma explicação para tal fenômeno. $\mathrm{O}$ primeiro diz respeito à transição brasileira: considerada extremamente longa quando comparada aos demais países latino-americanos, a nossa transição reuniu elementos conservadores e autoritários junto a elementos democratizantes, tornando-a uma transição híbrida. Como argumentou Weffort (1984; 1992), a democracia brasileira não nasceria 
transformadora, mas sim extremamente conservadora e com elementos identificados com o período autoritário com uma sobrevida duradoura na política.

O predomínio da direita no plano municipal desde o retorno das eleições diretas em 1982, observado por Meneguello (2007), é visível no Rio Grande do Sul, onde o PP é o maior partido do estado. Além disso, podemos entender a abrangência do PP como um aspecto da transição política para a democracia brasileira que reuniu elementos conservadores e democráticos em um mesmo sistema político.

$\mathrm{Na}$ medida em que as tradições conservadoras iam ficando para trás, muito delas se integraram ao sistema político democrático. A predominância do Partido Progressista - o partido fruto da Arena, sustentação parlamentar do regime ditatorial, conforme buscamos explicitar no histórico apresentado - é, portanto, resultado dos aspectos da transição e dos “entulhos autoritários" - mecanismos e instituições gestadas ao longo do período militar e para este favorecer, que ainda não foram superadas no atual sistema político - que partidos autoritários nos relegaram até os nossos dias.

O PP é um dos maiores partidos no RS, mas isto não corresponde à realidade de outros subsistemas partidários brasileiros. O fenômeno do "ainda todo poderoso" partido do regime civil-militar é resultado da combinação de um estado com tradição bipartidária, predomínio eleitoral da direita em municípios pequenos e uma transição lenta, pactuada e que teve como resultado elementos do regime anterior na democracia.

\section{REFERÊNCIAS}

ALMEIDA, L. C. 2004. PPB: origem e trajetória de um partido de direita no Brasil. São Paulo: USP. (Dissertação de Mestrado em Ciência Política).

BENEVIDES, M. V. 1981. A UDN e o udenismo: ambiguidades do liberalismo brasileiro (1945-1965). Rio de Janeiro: Paz e Terra.

DELGADO, L. A. 1989. N. PTB: do getulismo ao reformismo radical. (1945-1964). São Paulo: Marco Zero. 
FIGUEIREDO, A. C. 1993. Democracia on Reformas? Alternativas Democráticas à Crise Politica (1961-1964). São Paulo: Paz e Terra.

GRINBERG, L. 2009. Partido político ou bode expiatório: um estudo sobre a Aliança. Renovadora Nacional (Arena), 1965-1979. Rio de Janeiro: Mauad X, 2009.

HIPÓLITO, L. 1985. De raposas e reformistas: o PSD e a experiência democrática brasileira, 1945-64. Rio de Janeiro: Paz e Terra.

HIPÓLITO, L. De raposas e reformistas: o PSD e a experiência democrática brasileira,

KINZO, M. D. G. 1980. Novos Partidos: o início do debate. In: LAMOUNIER, B. Voto de Desconfiança: eleições e mudança política no Brasil: 1970-1979. Petrópolis: Vozes, São Paulo: CEBRAP, p. 217-260.

KINZO, M. D. G. 1988. Oposição e autoritarismo: gêneses e trajetória do MDB (1966-1979). São Paulo: Vértice, 1988.

LAMOUNIER, B. 1985. Apontamentos sobre a questão democrática brasileira. In: ROUQUIÉ, A.; LAMOUNIER, B.; SCHARZER, J. Como renascem as democracias. São Paulo: Brasiliense, p. 104-140.

LAMOUNIER, B. 1988. O "Brasil autoritário" revisitado: o impacto das eleições sobre a abertura. In: STEPAN, A. Democratizando o Brasil. São Paulo: Paz e Terra.

MADEIRA, R. M. 2006. Vinhos antigos em novas garrafas: a influência de ex-arenistas e exemedebistas no atual multipartidarismo brasileiro. Porto Alegre: UFRGS. (Tese de Doutorado em Ciência Política).

MADEIRA, R. M. 2011. A atuação de ex-arenistas e ex-emedebistas na Assembleia Nacional Constituinte. Revista Brasileira de Ciências Sociais, v. 26, n. 77, São Paulo, p. 189-203.

MADEIRA, R. M.; GIRARDI, D. A. 2014. O regime civil-militar e a política local: uma proposta de tipologia para análise de recrutamento e padrões de carreira de prefeitos nomeados no Rio Grande do Sul. Revista Teoria \& Pesquisa, v. 23, n. 2.

MAINWARING, S. 2001. Sistemas partidários em novas democracias: o caso do Brasil. Porto Alegre: Mercado Aberto, Rio de Janeiro: FGV.

MAINWARING, S.; MENEGUELLO, R.; POWER, T. 2000. Partidos conservadores no Brasil contemporâneo: quais são, o que defendem, quais são suas bases. Rio de Janeiro: Paz e Terra.

MARENCO, A. 2007. Devagar se vai longe? A transição para a democracia no Brasil em perspectiva comparada. In: MELO, C. R.; SAÉZ, M. A (orgs.). A Democracia Brasileira: balanços e perspectivas para o século 21. Belo Horizonte: UFMG, p. 73-108.

MENEGUELLO, R. 1989. PT: a formação de um partido 1979-1982. São Paulo: Paz e Terra. 
MENEGUELLO, R. 2007. Tendências eleitorais ao fim de 21 anos de democracia. In: MELO, C. R.; SAÉZ, M. A (orgs.). A Democracia Brasileira: balanços e perspectivas para o século 21. Belo Horizonte: UFMG, p. 367-404.

NICOLAU, J. 2012. Eleições no Brasil: do Império aos dias atuais. Rio de Janeiro: Zahar.

QUADROS, M. P. R. 2012. Progressistas, mas conservadores: a ideologia do Partido Progressista (PP) no Rio Grande do Sul. Porto Alegre: PUCRS. (Dissertação de Mestrado em Ciências Sociais).

REIS, F. W. 1983. O eleitorado, os partidos e o regime autoritário brasileiro. In: SORJ, B.; TAVARES, M. H. Sociedade e política no Brasil pós-64. São Paulo: Brasiliense, p. 91-131.

SANTOS, F. 2000. Escolhas Institucionais e Transição por Transação: Sistemas Políticos de Brasil e Espanha em Perspectiva Comparada. Dados, vol.43, n.4, Rio de Janeiro.

SHARE, D.; MAINWARING, S. 1986. Transição pela transação: democratização no Brasil e na Espanha. Dados,Revista de Ciências Sociais, Rio de Janeiro, vol. 29, n. 2, p. 207-236.

SKIDMORE, T. 1988. A lenta via brasileira para a democratização: 1974-1985. In: STEPAN, A (org.). Democratizando o Brasil. Rio de Janeiro: Paz e Terra, p. 27-82.

SOUZA, M. do C. C. 1985. A democracia populista, 1945-1964: bases e limites. In: ROUQUIÉ, A.; LAMOUNIER, B.; SCHARZER, J. Como renascem as democracias. São Paulo: Brasiliense, p. 73-103.

TRINDADE, H.; NOLL, M. I. 1991. Rio Grande da América do Sul: partidos e eleições (18231990). Porto Alegre: UFRGS/Sulina.

WEFFORT, F. 1984. Por que democracia?.São Paulo: Brasiliense.

WEFFORT, F. 1992. Qual democracia?.São Paulo: Brasiliense. 